EXPLORING ENERGY . .

\section{LEARNING ABOUT ENERGY}

\section{by David J. Rose}

A wide-ranging text for senior and graduate students that weaves technical and scientific information into an integrated current account of the field, including energy in its social and economic contexts, environmental consequences of energy use, energy conservation, fossil fuel resources and reserves, coal, nuclear power, solar power, and global electrification. A volume in the series Modern Perspectives in Energy

0-306-42124-0/528 pp/ill./1986/\$59.50 (\$71.40 outside US \& Canada)

text adoption price on orders of six or more copies: $\$ 39.50$

\section{NEW FROM PLENUM TRADE}

\section{EINSTEIN'S \\ DREAM}

The Search for a Unified

Theory of the Universe

by Barry Parker

"Completely non-mathematical, and beautifully written. Every page is a pleasure."

- Isaac Asimov

Award-winning writer Barry Parker depicts the men and their theories in the search for ultimate answers in modern physics.

0-306-42343-X/298 pp./cloth/\$18.95 (\$22.73 outside US \& Canada)

\section{SCIENCE TRIVIA}

\section{From Anteaters to}

\section{Zeppelins}

by Charles J. Cazeau

"A work of reference and a delightful bedside book."

-Glyn Daniel, University of Cambridge Let's Explore columnist to 81 Gannett newspapers presents questions that will pique the curiosities of the Ph.D. as well as the grade-schooler.

0-306-42.3.53-7/274 pp./cloth/\$17.95 (\$21.54 outside US \& Canada)

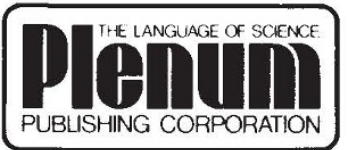

Plenum Publishing Corporation 233 Spring Street

New York, N.Y. 10013-1578

In the United Kingdom

88/90 Middlesex Street

London E1 7EZ. England

\section{Doctor, doctor...}

\section{Nicholas A. Rupke}

Frontiers of Learning: The Ph.D. Octopus. By Pjotr Hesseling. Foris Publications:* 1986. Pp. 204. Hbk £27.95, \$44; $p b k £ 17.95, \$ 27$.

"CAndidates must have a PhD ....". This stipulation has become a standard phrase in the job advertisement columns of science magazines. The $\mathrm{PhD}$, it would appear, has come to represent something of a passport to academic jobs and a union card for the would-be industrial scientist. Employers routinely use the qualification as a preliminary screening device to whittle down large numbers of applicants, often for jobs in which research training has little relevance. Although a result has been a steep rise in the number of people holding a doctorate, especially in the United States, relatively little is known about the $\mathrm{PhD}$ phenomenon. What is the function of the degree, its intrinsic worth, as the crowning feature of higher education? What fruits do we expect it to yield? What precisely should it represent? Is the recent multiplication of doctoral degrees a sign of academic health or a craze that is devaluing them?

It is questions such as these that Pjotr Hesseling, professor of business economics at the Erasmus University of Rotterdam, addresses in this book. He uses a comparative approach, looking at the history of the $\mathrm{PhD}$ in different countries and cultures. In its modern form the PhD is a German invention, the foundation of the University of Berlin in 1810 marking the beginning of higher education centred on the research imperative. The doctorate became less of an ornamental initiation rite and more of a serious research accomplishment, representing an independent and original contribution to knowledge, embodied in a book-length dissertation. From Germany the $\mathrm{PhD}$ moved to the United States (first award in 1861), Britain (1917) and more recently to Japan (1953), gradually penetrating the higher education system of each country.

In the course of its global advance, the $\mathrm{PhD}$ has been adapted to various indigenous cultural traditions. The European doctorate is to some extent still a shibboleth of originality and cultural authority (although the precise appreciation varies between disciplines and countries); the American doctorate is primarily used for pre-career training and as a certificate for entering the academic and other professions; the Asian doctorate, which Hesseling has studied mainly in Indonesia and Japan, is still in a formative phase, being

*PO Box 509, 3300 AM Dordrecht, The Netherlands, and PO Box 5904, Providence, Rhode Island 02903 , and $\mathrm{PO}$. made to fit old traditions of scholarship and wisdom on the one hand, and new, pragmatic considerations of statemanaged science policy on the other. Despite these differences, the American graduate school, envied for its productive efficiency, is increasingly becoming the model for the rest of the world.

Hesseling regrets the "Americanization" of the PhD, which is turning it into market-orientated training during which a candidate will often be assigned a narrowly defined topic within a pre-existing research programme. The $\mathrm{PhD}$, he believes,

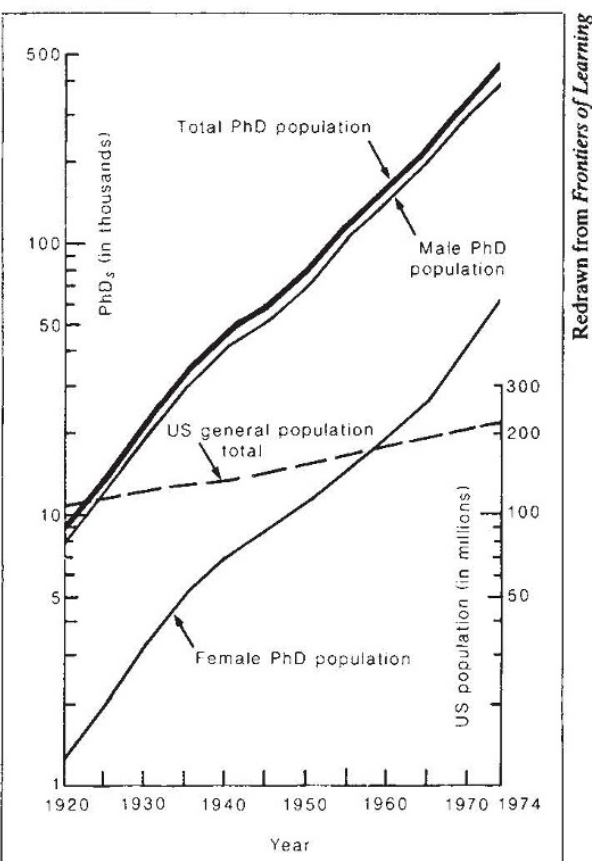

PhD explosion - the rise in the number of living holders of doctorates earned in the United States between 1920 and 1974.

is becoming too much part of governmentdirected science policy and of university administration preoccupied with production costs. Quality should be what matters most, but this feature is too elusive to be regulated to any great extent. Originality in research, although the outcome will be less certain, should have priority over completion rates - the reverse of what a recent OECD report, The Role and Function of Universities: Post-graduate Education in the 1980s, says on the subject.

Hesseling does not believe that the doctoral dissertation is a necessary complement to the education of all postgraduates. To him, the $\mathrm{PhD}$ should be part of a special "cultural mission" which includes testing received knowledge, overcoming boundaries between disciplines, institutions and nations, and striving for such ideals as disinterestedness and communalism. A doctorate should explore, as the title of his book states, "The Frontiers of Learning" and not be an overspecialized tentacle of "The Ph.D. Octopus" (a sub-title borrowed from the Harvard psychologist William James). 
To achieve this end, Hesseling advocates a European doctorate through the revitalization of the traditional academic peregrination which made use of the advantages of different systems. A code of practice should be adopted by the main European universities with, among other things, the abolition of fixed completion periods for doctoral projects, emphasis on interdisciplinary work, freedom for the candidate to select both topic and supervisors (the latter from more than one university), use of external examiners (already the practice in Britain) and publication of the thesis in a major language.

One can readily sympathize with these ideals. But given the increasingly tight and competitive marketplace, and given also the domination of the American system, the need to hold a doctorate as well as a bachelor's and a master's degree is greater than ever. It would therefore seem unrealistic to revert to a system of higher education in which the $\mathrm{PhD}$ is for the relatively few. Furthermore, Hesseling's ideals are to a large extent accommodated, especially in the Anglo-American world, by the network of post-doctoral fellowships which provide an opportunity to elaborate and publish doctoral theses. Many of these fellowships are held in institutes for advanced study with their interdisciplinary and international atmosphere. The Princeton Institute has been replicated, mutatis mutandis, not only in the United States itself but also in Germany, The Netherlands and Scotland. In England, several of the Oxbridge colleges give hospitality to advanced researchers in different disciplines.

Closer examination of these and related questions is obviously needed. Hesseling's book is seriously flawed stylistically there are innumerable mistakes of English usage and unnecessary repetitions of material, and many passages are exasperatingly vague. But he has brought a commendable breadth of approach to his subject, and has provided much food for thought for anyone interested in higher education.

Nicholas A. Rupke, Wolfson College, Oxford, $O X 26 U D, U K$, is a geologist and historian of science and medicine.

\section{Quantum question}

\section{Philip Pearle}

The Shaky Game: Einstein, Realism, and the Quantum Theory. By Arthur Fine. University of Chicago Press: 1986. Pp.179. $\$ 25, £ 21.25$.

EVEN such a loving biographer of Einstein and his physics as Abraham Pais seems embarrassed by Einstein's position on quantum theory. In his book 'Subtle is the Lord', Pais quotes Einstein - "I feel that the real joke that the eternal inventor of enigmas has presented us with has absolutely not been understood as yet" and then remarks, "It is believed by nearly all of us that the joke was understood soon after 1925 . . .". Given this belief, and the spectacular successes of quantum theory which nurture it, it is perhaps not surprising that sympathetic and careful analyses of Einstein's attitude have been lacking.

This lack is quite satisfactorily addressed in five (the second to sixth) of the nine essays which make up this book. The essays, most of which have been previously published, are clear, wellreasoned and appropriate settings for the gems they are studded with, quotes from the Einstein archives at Princeton. The sixth essay, "Einstein's Realism", forms a bridge to a rather different piece of country, three provocative articles on realism which reject both it and antirealism in favour of the author's own position, which he calls the "Natural Ontological Attitude" (NOA).

The second essay, which follows an introductory chapter, attacks the oftenpromulgated view that Einstein's position on quantum theory represented a "kind of scientific senility". After giving ample evidence that Einstein's way of thinking supported Poincaré's admiring assessment of ". . . the facility with which he adapts himself to new concepts. . . . He has not remained attached to classical concepts ...", Fine refreshingly concludes that ". . . it was Bohr not Einstein who felt bound by the classical concepts", and "in the end Einstein was more radical in his thinking.

The third essay details Einstein's route to the conviction that quantum theory is not ". . . in principle capable of producing a complete description of an individual physical system", and culminates in a discussion of the famous Einstein-Podolsky-Rosen paper. For those of us who have secretly never felt fully at ease with the tortuous arguments in that paper, and who have wondered how that master of clarity, Einstein, could have done this to us, Fine brings welcome relief. He shows just how complicated the argument of the paper is, presents evidence that Podolsky wrote it without revision by Einstein and analyses a simpler argument that Einstein sent to Schrödinger in a letter. The fifth essay also concerns letters from Einstein which stimulated Schrödinger while he was writing his famous paper on the cat paradox. This paper showed that quantum theory can predict a state for a cat that is a superposition of cat-alive plus cat-dead, an unrealistic situation for a single cat, thus supporting Einstein's statistical interpretation of quantum theory: "... . the description not of a single system but of an ensemble of systems". How delightful to learn that Einstein himself initiated this paradox, with an example of unstable gunpowder in a quantum state of unexploded plus exploded!

I found essay four on Einstein's statistical interpretation to be rather incomplete. Perhaps because Einstein felt that the de Broglie-Bohm "hidden variable" model is not fundamental enough, no discussion is given of this or the models of Wiener-Siegal or Nelson, which many feel are nice examples of how a statistical interpretation may function. Instead Fine presents some of his own work, a refutation of a model he calls "The Standard Answer" (a sharper earlier refutation due to Kochen and Specker is not mentioned) and a possibly satisfactory "Prism Model" whose similarity to the so-called "loophole" models and vulnerability to experimental refutation is not mentioned (until the last essay).

Einstein's realism is analysed next, understood as a faith, and dubbed "Motivational Realism". Fine shows that Einstein, while driven by a passionate realism, drew back from making logical assertions connecting physics to that reality. Apparently philosophers are not so judiciously reticent, and Fine rebuts both realist and antirealist positions. Instead he opts for NOA, a minimalist position, that accepts the truth of what is useful (for example the electron as a set of working ideas and experimental results) without further interpretation.

The NOA may be adequate for a spectator of the game of physics, but I do not see it as appropriate for a player. Fine tells us that NOA makes it easy to adopt "paradigm shifts", but that is passive behaviour. Physics, the active game of creating beautiful pictures with predictive power, was played so well by Einstein not least because of his realist faith.

Fine rather snidely compares the realist faith to religious faith. In the same vein I would add philosopher's faith (in unexamined axiomatic concepts), for it seems each philosopher is refuted by another on such "religious" grounds. There is nothing wrong with faith: all physicists act on more knowledge than they can prove. But in matters of faith, certainly evidence counts. The creative successes of realists over the centuries justify their leap of faith more than that of most others. And, although one might attribute the success of quantum theory in the past 60 years to nonrealists, in practice they deal with the reality of the concepts they use the way Bohr dealt with a horseshoe. He put one on his cottage door, and said, "No, I don't believe in it, but I understand the good luck comes even if you don't believe".

Philip Pearle is a Professor in the Department of Physics, Hamilton College, Clinton, New York 13323, USA. 